\title{
Continuous Monitoring: Look before You Leap*
}

\author{
Snorre Lindset \\ Trondheim Business School \\ HIST avdeling TØH, 7004 Trondheim, Norway. \\ e-mail: snorre.lindset@toh.hist.no \\ telephone: +4773559978 \\ facsimile: +4773559951 \\ and \\ Norwegian University of Science and Technology \\ Department of Industrial Economics \\ Svein-Arne Persson \\ Norwegian School of Economics and Business Administration \\ Department of Finance and Management Science \\ Helleveien 30, 5045 Bergen, Norway. \\ e-mail: svein-arne.persson@nhh.no \\ telephone: +4755959547 \\ facsimile: +4755959650 \\ and \\ Trondheim Business School
}

January 30, 2007

\begin{abstract}
In this paper we present a model for pricing credit risk protection for a limited liability non-life insurance company. The protection is typically provided by a guaranty fund. In the case of continuous monitoring, i.e., where the market values of the company's assets and liabilities are continuously observable, and where the market values of assets and liabilities follow continuous processes, the regulators can
\end{abstract}

${ }^{*}$ First version: November 7, 2005. This version: January 30, 2007. Earlier versions of this paper have been presented at the FIBE conference in Bergen, Jan 2007, and at faculty seminars at the Insurance and Risk Management Department at the Wharton School, University of Pennsylvania and at the Department of Finance and Management Science, Norwegian School of Economics and Business Administration. The paper was partially written while Lindset was a visiting scholar at the Insurance and Risk Management Department at the Wharton School, University of Pennsylvania. The authors would like to thank Knut Aase and Neil Doherty for comments and discussions. 
liquidate the insurance company at the instant the market value of its assets equals the market value of its liabilities, making the protection worthless. When jumps are included in the claims process, the protection provided by the guaranty fund has a strictly positive market value. We argue that the ability to continuously monitor the equity value of a company can be a new explanation for why jump processes may be important in the study of credit risk.

Keywords: credit risk for non-life insurers, guarantee fund, continuous monitoring, barrier options.

\section{Introduction}

This paper deals with credit risk. We propose a framework for valuing and analyzing the credit protection provided by a guaranty fund. Our main focus is on a limited liability non-life insurance company, although our approach is applicable to all limited liability corporations. We demonstrate that under our definition of bankruptcy the seminal Merton (1974) bankruptcy model breaks down if we assume that the market value processes for the assets and liabilities of the company are continuously observable. Continuously observable asset price processes are parts of the standard set-up in the continuous time finance model of Merton (1974), where the arbitrage argument depends on the possibility to continuously in time (i.e., at any time!) rebalance portfolios in order to replicate payoffs of contingent claims.

Supervision or regulation of the insurance industry is common in most, if not all, countries. It is considered desirable for a society to be able to trust its insurance industry. Regulation is imposed in order to to avoid hazardous management which again may lead to unwanted defaults. In most industrialized countries insurance policyholders are protected through a guaranty fund from losses in the case of insurance company insolvencies. The exact implementaton of such funds seems to vary from one country to another, e.g., in the USA the insurance industry itself, rather than the government, is the ultimate guarantor.

Cummins (1988) analyzes guaranty funds. The analysis is based on the seminal Merton (1974) model, which includes a fixed time horizon - interpreted by Cummins as the time when the guaranty fund audits the insurer. A guaranty fund typically audits the insurance companies at given points in time, for instance once a year. A possible bankruptcy is both detected and declared after an audit has taken place. Furthermore, Cummins (1988) argues that because of the physical characteristics of insurance risks, it is natural to include jumps in a realistic model of the claims against the insurance company. The use of risk based premiums for the bankruptcy protection from the guaranty fund is strongly advocated in his paper. Charging the insurers "correct" premiums is important because different insurers rep- 
resent different risks. Not differentiating among the level of risk can lead to moral hazard and unwanted economic behavior through unreasonable risk taking.

Instead of only letting the guaranty fund audit the insurer at a fixed point in time, we allow the guaranty fund to declare the insurer bankrupt the first time the market value of the assets are less than the market value of the liabilities. This is a natural definition of bankruptcy in our setting. For a general, non regulated company, our definition of bankruptcy is consistent with the use of bond covenants, i.e., the bond holders of a company have the right to declare the company default under certain conditions, the typical example is that the value of the company is below some threshold, see e.g., Black and Cox (1976). Similarly, a guarantee fund also represents the liability owners of the company. The alternative to let the liability owners determine default is to let the equityowners determine the default of the company. We do not consider this alternative realistic in the case of the insurance industry.

As Cummins (1988) we also use jump-diffusion processes to model the value of the insurer's assets and liabilities, but our starting point is somewhat different from Cummins' in that we use the EBIT approach of Goldstein, $\mathrm{Ju}$, and Leland (2001). By the EBIT approach the market value of the liabilities is calculated as the market value of all future discounted claims, and the market value of the assets is the market value of all future discounted premium income.

If there are no jumps in the price processes for the assets or the liabilities, our proposed monitoring mechanism completely eliminates the credit risk. Cummins' argument for including jumps is that jumps represent natural characteristics of insurance risk. The results of this paper therefore provide an additional argument for why it is important to include jumps in models of credit risk.

In potential applications of our model the main argument against continuous monitoring may be the cost of frequent audits. However, abstracting from jump risk, we show that the value of the equity of the insurer, which normally is a convex function of the value of the company, becomes linear under continuous monitoring. Thus, the value of the equity is simply the difference between the market value of the assets and the liabilities. Auditing a stock-listed insurer is therefore unnecessary. Financial analysts audit the insurer for free, and the guaranty fund only has to monitor the value of the insurer's equity, a quantity that can be observed on any Reuter screen. In the case of jump risk we show that increasing monitoring frequency severely reduces the cost of bankruptcy protection, although this cost is not completely eliminated as in the case without jumps.

The paper is organized as follows: In section 2 we present an EBIT based model of the insurance company. In section 3 we analyze the special case of our economic model without jumps. The analysis is extended in section 4 
to also include jumps in the claims process. Section 5 concludes the paper.

\section{A Model of a Property-Liability Insurer}

We consider an insurance company whose only liabilities are the potential insurance claims to its policyholders. We further take as given an equivalent martingale measure $Q$ where the discounted price processes for the company's assets and liabilities are martingales. The risk free interest is denoted $r$ and is assumed to be a constant.

Let $x_{s}$ be the rate of new claims filed against the insurer at time $s>t$, $t$ represents a fixed, initial point in time. Under the measure $Q x_{s}$ is given by

$$
x_{s}=x_{t} e^{\left(\mu_{x}-\gamma m-\frac{1}{2}\left\|\sigma_{x}\right\|^{2}\right)(s-t)+\sigma_{x} W_{s}} \prod_{i=1}^{N_{s}} Y_{i} .
$$

Here $N_{s}$ is a Poisson process with constant intensity $\gamma, W_{s}$ a two-dimensional vector of independent, standard Brownian motions, $\mu_{x}$ is a drift parameter, $\sigma_{x}=\left(\sigma_{11}, \sigma_{12}\right)$, where the $\sigma_{i j}$ 's are constants, is the volatility vector of the continuous part of the process. Here the $Y_{i}$ 's represent a sequence of jump magnitudes and are independent and identically distributed. In addition, the $Y_{i}$ 's are independent of $W_{s}$ and $N_{s}$, and $W_{s}$ and $N_{s}$ are independent. In particular we assume that $\ln \left(Y_{i}\right) \sim \mathcal{N}\left(a, b^{2}\right)$. Also, $m=\mathrm{E}\left[Y_{i}\right]-1=$ $e^{a+\frac{1}{2} b^{2}}-1$. Every time a jump occurs, the level of $x_{t}$ is permanently changed.

Observe that $E\left[\prod_{i=1}^{N_{s}} Y_{i} \mid \mathcal{F}_{t}\right]=e^{\gamma m(s-t)}$, so $E\left[x_{s} \mid \mathcal{F}_{t}\right]=x_{t} e^{\mu_{x}(s-t)}$. The initial values $W_{t}=N_{t}=0$. Finally, $\mathcal{F}_{t}$ is a filtration, interpretable as the information available at time $t$, and the notation $\|\cdot\|$ represents the standard Euclidean norm.

The time $t$ market value of the stream of claims is calculated as the expected discounted value under the equivalent martingale measure $Q$, i.e.,

$$
L_{t}=E\left[\int_{t}^{\infty} e^{-r(s-t)} x_{s} d s \mid \mathcal{F}_{t}\right]=\frac{x_{t}}{r-\mu_{x}}
$$

where by assumption $\mu<r$. Expression (2) is some places known as Gordon's formula.

At the future fixed time $T>t$ the random value of the liabilities is given by

$$
L_{T}=L_{t} e^{\left(\mu_{x}-\gamma m-\frac{1}{2}\left\|\sigma_{x}\right\|^{2}\right)(T-t)+\sigma_{x} W_{T}} \prod_{i=1}^{N_{T}} Y_{i},
$$

where $L_{t}$ is given by (2). 
In a similar manner, we let the rate of premium income at time $t$ be given by

$$
p_{s}=p_{t} e^{\left(\mu_{p}-\frac{1}{2}\left\|\sigma_{p}\right\|^{2}\right)(s-t)+\sigma_{p} W_{s}},
$$

where $\mu_{p}$ is a constant and $\sigma_{p}=\left(\sigma_{21}, \sigma_{22}\right)$, with constant $\sigma_{i j}$.

The time $t$ market value of the future stream of premium income is the insurer's assets and is given by

$$
A_{t}=E\left[\int_{t}^{\infty} e^{-r(s-t)} p_{s} d s \mid \mathcal{F}_{t}\right]=\frac{p_{t}}{r-\mu_{p}} .
$$

At the future time $T>t$ the random value of the assets is

$$
A_{T}=A_{t} e^{\left(\mu_{p}-\frac{1}{2}\left\|\sigma_{p}\right\|^{2}\right)(T-t)+\sigma_{p}^{\top} W_{T}} .
$$

Note that both future asset and liability values have similar probability distributions as in the model in Cummins (1988).

\section{The Diffusion Case}

In this section we assume that $Y_{i}=1$ for all $i$ (equivalently that $a=b=$ 0 , so $m=0$ ), i.e., there is no jump risk in the model and it is therefore equivalent to a pure diffusion model where the processes for the value of both assets and liabilities have continuous sample paths.

\subsection{Audit only at time $T$}

In the model in Cummins (1988) a guaranty fund will evaluate the insurer at some future point in time $T$, and if the insurer is insolvent, i.e., $A_{T}<L_{T}$, the insurance company is dissolved and the policyholders are compensated for their claims against the insurer. The shortage of funds, i.e., $L_{T}-A_{T}$ is supplied by the guaranty fund. Thus, the payment at time $T$ by the guaranty fund is

$$
\pi_{T}=\max \left(L_{T}-A_{T}, 0\right) .
$$

Since both the assets and the liabilities follow stochastic processes, the contingent cashflow in (5) can be interpreted as an exchange option and has time $t$ market value (see e.g., Fischer (1978) and Margrabe (1978)) ${ }^{1}$

$$
\pi_{t}=L_{t} e^{\left(\mu_{x}-r\right)(T-t)} \Phi\left(d_{1}\right)-A_{t} e^{\left(\mu_{p}-r\right)(T-t)} \Phi\left(d_{2}\right),
$$

where $\Phi(\cdot)$ is the standard normal distribution function,

$$
d_{1}=\frac{\ln \left(\frac{L_{t}}{A_{t}}\right)+\left(\mu_{x}-\mu_{p}+\frac{1}{2}\left\|\sigma_{x}-\sigma_{p}\right\|^{2}\right)(T-t)}{\left\|\sigma_{x}-\sigma_{p}\right\| \sqrt{T-t}},
$$

\footnotetext{
${ }^{1}$ Note that this is a slight extension of the Fischer (1978) and Margrabe (1978) formula in that both the assets and the liabilities have a drift rate different from the risk free rate.
} 
and

$$
d_{2}=d_{1}-\left\|\sigma_{x}-\sigma_{p}\right\| \sqrt{T-t}
$$

The guaranty fund covers the policyholders' economic losses in case the insurer is declared bankrupt at time $T$, but is not in a position where it can take any actions against the insurer to limit its losses if the insurer's financial situation becomes difficult prior to time $T$. Action can only be taken at time $T$. A possible real world explanation for this model may be that the values of the assets and liabilities may not be readily available in real life. Detailed information about these values is only available after a closer revision of the insurer. This explanation may seem somewhat extreme, but is not necessarily unrealistic. However, it contradicts the assumption of continuous observable price processes inherent in the Merton model (which is implicitly used here).

\subsection{Continuous auditing}

Consider now the opposite extreme case, i.e., continuous monitoring. If the values of the assets and liabilities are more easily available, continuous monitoring can be performed. We suppose this is the case and that the insurer will be liquidated the first time $A_{s} \leq L_{s}, s \in(t, T]$. We also assume that the policyholders' claims have higher priority than the equity at the time of bankruptcy. Define $\tau$ as

$$
\tau=\inf _{s \in(t, T]}\left(\frac{L_{s}}{A_{s}} \geq 1\right)
$$

i.e., $\tau$ is the time the insurer is insolvent and therefore will be declared bankrupt. The cashflow from the guaranty fund is now

$$
\pi_{\tau}=\max \left(L_{\tau}-A_{\tau}, 0\right) 1_{\tau \leq T} .
$$

Note that this casflow is identical to the cashflow from a barrier exchange option. The first time $L_{s}$ hits $A_{s}$ from below, the option expires immediately. Thus, the guaranty fund has issued a barrier exchange option expiring at whatever comes first of the random stopping time $\tau$ or $T$. Because the option matures the first time $L_{s}=A_{s}$, it must always be the case that $\pi_{\tau}=0$, and the option issued by the guaranty fund must therefore be worthless. ${ }^{2}$ Thus, by invoking continuous monitoring of the insurance company's balance sheet and liquidating the insurer the first time his assets and liabilities have the same market value, the guaranty fund will never have to pay money in case the insurer is declared bankrupt. In the case of only time $T$ auditing,

\footnotetext{
${ }^{2}$ For a discussion of this kind of barrier exchange options, see e.g., Lindset and Persson (2006).
} 
the guaranty fund is a vehicle providing financial security for the policyholders. Under continuous monitoring the guaranty fund will never have to pay money and has now changed its purpose into a vehicle for surveillance of an insurance business with insolvency risk.

Cummins (1988) says that insurers are subject to a revision once a year with more detailed revisions every three to five years. Revisions are costly and are therefore not performed more frequently. However, we argue that in the diffusion case this is not necessarily a problem for stock listed insurers. To see this, let us take a closer look at an insurer's equity.

The purpose of the guaranty fund is to protect the policyholders from the credit risk of the insurer. In the case where the insurer has unlimited liability, there is in principle no credit risk for the policyholders. The value of the equity of the insurer at time $s$ is then $A_{s}-L_{s}$. In practice most insurers have limited liability. In this case the guaranty fund pays $\pi_{T}=L_{T}-A_{T}$ in case of bankruptcy and zero otherwise. This guaranty is a state contingent claim for the insurer, and the value at time $t<T, \pi_{t}$, increases the value of the equity by the same amount, compared to the case with unlimited liability. When the guaranty fund instead uses continuous monitoring, we saw above that $\pi_{s}=0$, thus, even though the insurer may have limited liability, the value of the equity is the same as when he has unlimited liability, i.e., $E_{s}=A_{s}-L_{s}$. Publicly traded companies are subject to "continuous" scrutiny by investors and financial analysts afraid of loosing their money and that are looking for new investment opportunities. The guaranty fund does therefore only have to look to the financial market and see how they value the shares of the insurer. If the value gets low, this is evidence that $L_{s}$ is approaching $A_{s}$, and closer monitoring must therefore be implemented. Even though the guaranty fund may use continuous monitoring, the financial market can probably perform most of the monitoring, severely reducing the monitoring costs for the guaranty fund and almost eliminating the costs from insolvency.

The difference between Cummins' monitoring only at time $T$ and our proposed continuous monitoring has the same effect as including a covenant in a debt contract, a feature frequently discussed in corporate finance. In the model by Cummins (1988), the value of the guarantee provided by the guaranty fund is convex in the difference $L_{s}-A_{s}$. From the discussion above, it is clear that this also means that the value of the equity is convex in this difference. By increasing the number of monitoring points, the value of the equity becomes less convex, and in the limit (i.e., under continuous monitoring), the value of the equity is linear in $L_{s}-A_{s}$. Thus, our proposed monitoring scheme represents a "de-convexification" of the equity. 


\section{The General Case}

\subsection{Audit only at time $T$}

Jump-diffusion models have been proposed in the finance literature as a possible extension by Merton (1976) in the pricing of options and have found some empirical support in Jorion (1988). The importance of jumps is quite intuitive for a property-liability insurer; earthquakes, hurricanes, and changes in judicial interpretations can all lead to sudden shifts in the value of an insurer's liabilities. Cummins (1988) therefore proposes to model the market value of the liabilities by a jump-diffusion model.

As mentioned in section 2, we assume, for some constants $a$ and $b$ that $\ln Y_{i} \sim \phi\left(a, b^{2}\right)$, i.e., the jumps are lognormally distributed. Let $n$ be a counter which counts the number of jumps in the claims process. Following the lines in Merton (1976), it can be shown that $\Pi_{t}$, the initial market value of the guarantee provided by the guaranty fund, is given by (a related formula is derived in Lindset (2007), where a proof can be found)

$$
\Pi_{t}=\sum_{n=0}^{\infty} e^{-\gamma(T-t)} \frac{(\gamma(T-t))^{n}}{n !} \pi_{t}^{n},
$$

where

$$
\pi_{t}^{n}=L_{t} e^{\left(\mu_{x}-r-\gamma m\right)(T-t)+n \ln (1+m)} \Phi\left(d_{1}^{n}\right)-A_{t} e^{\left(\mu_{p}-r\right)(T-t)} \Phi\left(d_{2}^{n}\right) .
$$

Here the functions $d_{1}^{n}$ and $d_{2}^{n}$ are defined as

$$
d_{1}^{n}=\frac{\ln \left(\frac{L_{t}}{A_{t}}\right)+\left(\mu_{x}-\mu_{p}-\gamma m+\frac{1}{2} \sigma_{n}^{2}\right)(T-t)+n \ln (1+m)}{\sigma_{n} \sqrt{T-t}}
$$

and

$$
d_{2}^{n}=d_{1}^{n}-\sigma_{n} \sqrt{T-t},
$$

respectively. The volatility $\sigma_{n}$ is defined as

$$
\sigma_{n}=\sqrt{\left\|\sigma_{x}-\sigma_{p}\right\|^{2}+n b^{2} /(T-t)} .
$$

Notice that the formula in (6) is close to a weighted sum of exchange options in a diffusion model. The inclusion of the jumps has affected the terminal distributions for the asset and the liability values, but the timing of the jumps does not affect the cost for the guaranty fund. Much of the generality that is gained by including the jumps could therefore have been gained by adjusting the input parameters in the diffusion model, for instance by using an "implied volatility approach". 


\subsection{Continuous auditing}

When we allow for more frequent monitoring of the insurer, the inclusion of jumps becomes very important. In the case with continuous monitoring as analyzed above, we found the guaranty fund to have issued an exchange option that is worthless and the value of the equity is simply the difference between the value of the assets and the liabilities, i.e., the option element of the equity is worthless. The insurer is declared bankrupt immediately when the ratio $\frac{L_{t}}{A_{t}}$ hits one from below. Because the sample paths for the stochastic process $\left\{A_{t}\right\}_{t \in[0, T]}$ are discontinuous in a jump-diffusion model, we have that $P\left(\left\{\frac{L_{t-}}{A_{t-}}<1\right\} \cap\left\{\frac{L_{t}}{A_{t}}>1\right\}\right)>0$. In words, the guaranty fund can observe a solvent insurer and in an instant of time later observe that the ratio between the value of the liabilities and the assets makes a jump so that the insurer becomes insolvent. The associated cost for the guaranty fund is $L_{t}-A_{t}>0$, yielding a strictly positive value of the issued exchange option.

Table 1 shows how the market value of the exchange option issued by the guaranty fund varies when the continuous monitoring of the insurer is approximated by different numbers of monitoring points. ${ }^{3}$ It is clear that a high number of monitoring points is required for the value of the issued guarantee to converge to zero, i.e., the value when the insurer is monitored continuously in the diffusion model. ${ }^{4}$ Although the convergence rate is also slow in the jump-diffusion model, we can clearly see that the value does not converge to zero, demonstrating that even when the insurer is monitored continuously the guarantee has positive value. No matter how the volatilities and the initial values of the assets and the liabilities are changed in the diffusion model, this result cannot be obtained since the value is always zero. ${ }^{5}$ Explicitly modeling the jumps is therefore important in this case.

The market values of the guarantee provided by the guaranty fund reported in Table 1 contain more information than the convergence rate to continuous monitoring. They also show that less frequent monitoring reduces the market value of the guarantee. For instance, two monitoring points a year reduces the market value of the guarantee to 0.463 and 0.707 for the diffusion and the jump-diffusion case, respectively. Auditing the insurer quarterly further reduces the market values to 0.408 and 0.614 . If the guaranty fund finds it difficult to rely on information from the financial

\footnotetext{
${ }^{3}$ The calculations are performed using Ox, see Doornik (1999).

${ }^{4}$ Faster convergence can be obtained if the insurer is declared insolvent the first time$$
\frac{L_{t}}{A_{t}}=e^{-0.5826\left\|\sigma_{x}-\sigma_{p}\right\| \sqrt{d t}},
$$

where $d t$ is the time between each monitoring point (see e.g., Broadie, Glasserman, and Kou (1997)).

${ }^{5}$ The uninteresting case where the insurer is insolvent at the begining of the period is disregarded here.
} 
Table 1: Time zero market values of the guaranty issued by the guaranty fund in the diffusion and the jump-diffusion model. Parameter values are: $x_{0}=10, \sigma_{11}=0.2, \sigma_{12}=0, \mu_{x}=0.05, p_{0}=12, \sigma_{21}=0.1, \sigma_{22}=0.05$, $\gamma=1, a=-0.00125, b=0.05, r=0.1, \mu_{p}=0.05$, and $T=1$. Monte Carlo simulations with 100,000 runs estimate the market values. The continuous monitoring of the insurer is approximated with a finite number of monitoring points, ranging from $10^{0}$ to $10^{5}$.

\begin{tabular}{lcccccc}
\hline \hline $\begin{array}{l}\text { Monitoring } \\
\text { points }\end{array}$ & $10^{0}$ & $10^{1}$ & $10^{2}$ & $10^{3}$ & $10^{4}$ & $10^{5}$ \\
\hline $\begin{array}{l}\text { Diffusion } \\
\text { Model }\end{array}$ & 0.503 & 0.307 & 0.124 & 0.044 & 0.014 & 0.005 \\
$\begin{array}{l}\text { Jump-diffusion } \\
\text { Model }\end{array}$ & 0.780 & 0.478 & 0.228 & 0.124 & 0.089 & 0.057 \\
\hline
\end{tabular}

market and they know the cost of revising an insurer, an optimal frequency of audits can be estimated.

Although the focus in this paper has been on property-liability insurance, the main idea in this paper, i.e., the benefits of more frequent monitoring, has a much wider field of applications and implications. It is also common to have guaranty funds protecting holders of life insurance policies. Much of the same reasoning as we have done for the guaranty fund for property-liability insurance also applies for the guaranty funds used in life insurance. This is also true for deposit insurance used to protect customers from (savings) bank default. Even banks themselves try to get a better understanding of their loan customers. This basically requires two things; more frequent monitoring of the customers and better ways to evaluate each customer at each monitoring point. For a bank it is relatively easy to locate the least risky borrowers and the most risky borrowers. The difficult part is to distinguish between the different customers in the middle. The bank that has the best system to also categorize these customers clearly has an edge when it comes to setting competitive borrowing rates to the above average solid customers. This requires both good and frequent monitoring.

\section{Conclusions}

In this paper we present a framework based on the EBIT approach and Cummins (1988)'s jump-diffusion model for valuing the credit protection provided by a guaranty fund. We show that if jumps are not included in the model and the insurer can be monitored continuously, the credit risk vanishes, clearly demonstrating the importance of including jumps. We explain in which sense more frequent monitoring represents de-convexification 
of the equity. Monitoring costs may be reduced by exploiting the monitoring that already takes place for stock-listed companies in the financial marketplace. Most of the information needed by the guaranty fund is present in the quoted stock price of the insurer.

\section{References}

Black, F. and Cox, J. (1976). "Valuing Corporate Securities: Some effects of bond indenture provisions", Journal of Finance, 31, 351-367.

Broadie, M., Glasserman, P., and Kou, S. (1997). "A Continuity Correction for Discrete Barrier Options", Mathematical Finance, 2(4), 325-348.

Cummins, J. D. (1988). "Risk-Based Premiums for Insurance Guaranty Funds", Journal of Finance, 43(4), 823-839.

Doornik, J. (1999). Object-Oriented Matrix Programming Using $O x$. Timberlake Consultants Press and Oxford (www.nuff.ox.ac.uk/Users/Doornik), London.

Fischer, S. (1978). "Call Option Pricing When the Exercise Price is Uncertain, and the Valuation of Index Bonds", Journal of Finance, 33, $169-176$.

Goldstein, R., Ju, N., and Leland, H. (2001). "An EBIT-Based Model of Dynamic Capital Structure", Journal of Business, 74 (4), 483-512.

Jorion, P. (1988). "On Jump Processes in the Foreign Exchange and Stock Markets", Review of Financial Studies, 1(4), 427-445.

Lindset, S. (2007). "Pricing American Exchange Options in a Jump-diffusion Model", Forthcomming in the Journal of Futures Markets.

Lindset, S. and Persson, S.-A. (2006). "A Note on a Barrier Exchange Option: The World's Simplest Option Formula?", Finance Research Letters, 3(3), 207-211.

Margrabe, W. (1978). "The Value of an Option to Exchange One Asset for Another", Journal of Finance, 33, 177-186.

Merton, R. C. (1974). "On the Pricing of Corporate Debt: The Risk Structure of Interest Rates", Journal of Finance, 29(2), 449-470.

Merton, R. C. (1976). "Option Pricing when Underlying Stock Returns are Discontinuous", Journal of Financial Economics, 4 (3), 125-144. 